\title{
Plasma exchange in the treatment of Refsum's disease (heredopathia atactica polyneuritiformis)
}

\author{
Danielle Harari, F B Gibberd, J P R Dick, M C Sidey
}

\begin{abstract}
Five cases of heredopathia atactica polyneuritiformis (HAP-Refsum's disease) were treated by serial plasma exchanges. In all patients a reduction in calorie intake and body weight had been associated with a rise in plasma phytanic acid, followed by an exacerbation of the ataxia and neuropathy. Lowering the plasma phytanic acid by plasma exchange produced a rapid clinical improvement. The main indication for plasma exchange in HAP is a severe or rapidly worsening clinical condition. A lesser indication is failure of dietary management to reduce a high plasma phytanic acid level.
\end{abstract}

Heredopathia atactica polyneuritiformis (HAP) better known as Refsum's disease ${ }^{1}$ is characterised by retinitis pigmentosa, anosmia, and ataxia associated with other disorders due to an accumulation in the patient's body of phytanic acid which cannot be metabolised. ${ }^{2}$ The clinical signs directly related to plasma phytanic acid levels are neuropathy, ichthyosis, kidney malfunction and cardiac arrhythmias. ${ }^{3}$ The use of therapeutic plasma exchange in neurological disorders has been the subject of a Consensus Conference ${ }^{4}$ and leading $\operatorname{articles}^{56}$ without mentioning HAP. The condition of our five cases improved after removal of plasma phytanic acid by plasma exchange (PE), thus fulfilling the conference's indications for $\mathrm{PE}^{4}$

Phytanic acid is a branched-chain fatty acid derived from dietary phytanic acid and absorbed phytol..$^{7}$ Alpha-oxidation is necessary for the catabolism of phytanic acid ${ }^{2}$ as the methyl group on its third carbon atom prevents betaoxidation, the usual method of fatty acid metabolism. ${ }^{8}$ In HAP there is an absence of the enzyme needed for alpha-oxidation.

Less than $1 \%$ of ingested phytanic acid is excreted in the urine and phytanic acid excreted in bile is mostly reabsorbed. Phytanic acid therefore accumulates in those with HAP almost at the rate of dietary intake which is $160-320 \mathrm{micromol} /$ day. A small amount of phytanic acid can be metabolised by omega-oxidation, a pathway much used in normal people, but the amount metabolised is only about 32-64 micromol/day.

In patients with HAP phytanic acid is predominantly stored in adipose tissue where it is harmless but it is also incorporated into the brain, myelin sheaths, kidneys and liver where damage can be caused. In a normal person the plasma phytanic acid level is below 33 micromols $/ 1$. In a patient with untreated Refsum's disease the levels vary between 992 and $6400 \mathrm{micromols} / \mathrm{l}$. For the majority of patients a diet low in phytanic acid is the most important aspect of management. ${ }^{3}$ In critically ill patients where there is inadequate time for dietary restriction to be effective phytanic acid can be removed by PE. Phytanic acid in the blood is bound to lipoproteins and cannot be removed by haemodialysis but is removed by PE.

\section{Patients}

All the patients had HAP. The case histories of the first three patients have been published elsewhere. ${ }^{3}$ The aspects of the cases histories relevant to PE for patients 4 and 5 are given. The plasma phytanic acid levels are shown in the table. Of the 22 patients with HAP who have attended Westminster Hospital only five have needed PE. The condition of the others has been controlled solely by dietary restriction.

Patient 1 had $\mathrm{PE}$ at the age of 32 years. Before this his weight was $59 \mathrm{~kg}$, having fallen $16 \mathrm{~kg}$ in nine years, particularly in the previous two months. He had severe ataxia and severe proximal (Grade 2 hip flexors) and distal (Grade 1 ankle dorsiflexion) weakness. He could do very little as he was unable to feed himself and was confined to bed. He had ichthyosis. Three weeks after the first PE he began to improve and was able to walk. Two months later he had grade 4 power of hip flexion, Grade 3 ankle dorsiflexion, his ichthyosis had disappeared and his weight had risen to $73 \mathrm{~kg}$.

Patient 2 had PE at the age of 53 years. Before this he had gross ataxia and difficulty in walking which improved within two weeks of PE. He had lost $3 \mathrm{~kg}$ in the three months before PE and regained his original weight within nine months.

Patient 3 had PE at the age of 40 years. Before PE he had severe ataxia and distal weakness (Grade 4 dorsiflexion of the ankles). After PE his ataxia and weakness improved but more slowly and less dramatically than for the other patients possibly because he was less disabled and his plasma phytanic acid levels were lower. Before PE he weighed $58 \mathrm{~kg}$ and 10 months after $72 \mathrm{~kg}$.

Patient 4, a 26 year old housewife developed retinitis pigmentosa at the age of nine years. She had remained well until the age of 25 when anorexia with a weight loss of $6 \mathrm{~kg}$ to $36.5 \mathrm{~kg}$ in two months was precipitated by marital 
Table Plasma exchange

\begin{tabular}{|c|c|c|c|c|c|}
\hline Patient & $\begin{array}{l}\text { Plasma volume } \\
\text { exchange } \\
\text { mls }\end{array}$ & $\begin{array}{l}\text { Plasma phytani } \\
\text { Pre-exchange } \\
\text { micromols/l }\end{array}$ & $\begin{array}{l}\text { ic acid } \\
\text { Post-exchange } \\
\text { micromols/l }\end{array}$ & $\begin{array}{l}\text { Phytanic ac } \\
\text { Micromols }\end{array}$ & d removed \\
\hline $\begin{array}{r}1 \text { day } \begin{array}{r}1 \\
8 \\
18\end{array} \\
\quad\end{array}$ & $\begin{array}{l}1950 \\
2250 \\
2300\end{array}$ & $\begin{array}{r}2083 \\
993 \\
513\end{array}$ & $\begin{array}{r}1346 \\
641 \\
353\end{array}$ & $\begin{array}{r}3500 \\
1483 \\
738\end{array}$ & 5721 \\
\hline $\begin{array}{ll}2 \text { day } \begin{array}{l}1 \\
3 \\
\\
\end{array} \\
& 7\end{array}$ & $\begin{array}{l}1920 \\
2150 \\
2250\end{array}$ & $\begin{array}{l}2244 \\
1602 \\
1378\end{array}$ & $\begin{array}{r}1026 \\
865 \\
833\end{array}$ & $\begin{array}{r}2953 \\
2279 \\
802\end{array}$ & 6034 \\
\hline $\begin{array}{l}3 \text { day } \begin{array}{r}1 \\
4 \\
15\end{array} \\
\quad\end{array}$ & $\begin{array}{l}2100 \\
2000 \\
2000\end{array}$ & $\begin{array}{l}706 \\
449 \\
384\end{array}$ & $\begin{array}{l}514 \\
288 \\
353\end{array}$ & $\begin{array}{l}741 \\
513 \\
257\end{array}$ & 1511 \\
\hline $\begin{array}{rr}4 \text { day } 1 \\
6 \\
6 \\
13 \\
20\end{array}$ & $\begin{array}{l}1400 \\
1470 \\
1675 \\
1410\end{array}$ & $\frac{6410}{\overline{1474}}$ & $\begin{array}{c}3333 \\
\overline{1699} \\
865\end{array}$ & $\begin{array}{l}4590 \\
2953 \\
2408 \\
1637\end{array}$ & 11588 \\
\hline $\begin{array}{ll}5 \text { day } \begin{array}{r}1 \\
8 \\
\\
15\end{array}\end{array}$ & $\begin{array}{l}1500 \\
1600 \\
1700\end{array}$ & $\begin{array}{l}2133 \\
3088 \\
2570\end{array}$ & $\begin{array}{l}1298 \\
1680 \\
1678\end{array}$ & $\begin{array}{l}3380 \\
3240 \\
2997\end{array}$ & 11473 \\
\hline
\end{tabular}

problems and depression. She complained of loss of smell and hearing and of unsteadiness on walking. She developed rapidly progressive sensorimotor neuropathy so that on admission she could not walk or wash herself. She had anosmia, profound deafness and a visual acuity of $6 / 12$. She had no voluntary finger movements and her resting ECG was abnormal with widespread $\mathrm{T}$-wave inversion and symptomatic episodes of nodal bradycardia and sinus arrest. Her CK, HBD and ESR were elevated and the urine contained aminoacids. An echocardiogram showed cardiomyopathy. Plasma phytanic acid on admission was 6410 micromol/1. Within three days of admission PE was carried out. Immediately afterwards her nodal arrhythmia disappeared and the aminoaciduria cleared. She began a liquid no phytanic acid diet administered by naso-gastric tube. One month after PE the peripheral sensory neuropathy was less marked and she had a flicker of finger movement. Her weight was unchanged. With dietary control improvement continued over the next year. Nine months after PE her anosmia, deafness and poor vision were unchanged but her weight had increased by $4 \mathrm{~kg}$ and she was able to use her hands and arms normally and was able to walk reasonably despite poor balance and numbness in the feet. An echocardiogram showed an abnormal myocardium and she maintained her plasma phytanic acid between 603 and $974 \mathrm{micromol} / 1$.

Patient 5, a 25 year old secretary had first noticed mild deafness four years previously. This occurred in episodes lasting 20 minutes. In the year before admission she had lost $25 \mathrm{~kg}$ in weight due to a deterioration in her diet. Three months before admission she had been well and was able to jog. Over the two months before admission she developed anorexia, nausea and a progressive sensorimotor polyneuropathy and was admitted unable to stand or dress herself due to profound gait and limb ataxia. During the two weeks before admission she had longer and more severe episodes of deafness lasting several hours and tinnitus. She weighed $44 \mathrm{~kg}$ and examination showed hyposmia, bilateral visual acuity of $6 / 9$, bilateral concentric field restriction and a pigmentary retinopathy. Auditory acuity was diminished and it was necessary to conduct some of the consultation in writing. Her fourth metatarsals were shortened in both feet and there was mild generalised ichthyosis. She had a mild distal weakness (grade 4) and a glove (midforearm) and stocking (midthigh) pinprick impairment. She was areflexic. She had a profound hypokalaemic alkalosis which required potassium replacement. Her CK was mildly elevated and there were aminoacids in her urine. The ECG and echocardiogram were normal. The cortical components of her visual and auditory evoked potentials were delayed.

During the first week in hospital her deafness increased rapidly. The tinnitus disappeared as the deafness became denser. In view of the profound anorexia, and increasing weight loss and deafness PE was started 12 days after admission. She was fed a liquid phytanic acid free diet by nasogastric tube for two months.

Her symptoms of nausea and lassitude responded promptly to PE though her weight remained static. After three weeks of nasogastric feeding her weight began to increase and she was discharged after three months weighing $54 \mathrm{~kg}$. Her gait and ataxia had improved though she had residual foot drop on the right and sensory symptoms in the finger tips and toes. She required a hearing aid. Sixteen weeks after PE she was walking well.

\section{Methods}

Plasma exchange

Three to four sessions of PE were performed on each patient over a period of seven to 22 days. The Amino Celltrifuge Continuous Flow Cell Separator was used with heparin as the anticoagulant for patients 1 and 2 . For patients 3, 4 and 5 a Haemonetics Model 30 Plasma Exchanger (Continuous Flow) was used with citrate-dextrose as anticoagulant. Replacement fluid to equal the exchange volume consisted of purified protein fraction for patient 3 , a mixture of purified protein fraction and fresh frozen plasma for patients 1 and 2, a mixture of human salt-free albumin and fresh frozen plasma for patient 4 and human albumin for patient 5 .

Plasma phytanic acid levels were measured using gas liquid chromatography. ${ }^{910}$

\section{Results}

The Plasma Exchange data are shown in the table. All the patients benefited from PE. Clinically there was marked improvement in the neuropathy and ataxia. Analysis of the PE effluent showed that the process removed a considerable amount of phytanic acid from the patient. Three or four PEs removed the equivalent of 10 to 70 days intake in an average Western European diet. This shows that PE can make a significant difference to the phytanic acid status of the patient.

\section{Discussion}

Over the last 19 years there have been several reports of patients with HAP treated by PE. As with our findings all these reports have shown that $\mathrm{PE}$ reduces the level of plasma phytanic acid resulting in an improvement in the patients' clinical condition. The significance of this study is that it considers the role of PE in a large group (22) of patients and defines its 
limited indications for the few (5) patients with severe illness. Previous authors have treated only one or two patients.

Lundberg et al ${ }^{11}$ were the first to describe the use of PE in HAP. They treated two very ill siblings who, having failed to respond to dietary restriction, had very high levels of plasma phytanic acid. Over 26 weeks the sister had 17 PEs. Her less severely affected brother had ten PEs over 16 weeks. Both patients were put on diets restricted in phytanic acid. From the beginning of treatment there was marked improvement clinically and in nerve conduction. Penovich et al ${ }^{12}$ treated a 39 year old woman with severe neurological disability with twice weekly PE for three months and less frequent $P E$ subsequently. The patient showed symptomatic improvement within 10 days and by three months was able to walk unaided. Moser et al ${ }^{13}$ performed 21 PEs on one patient over a period of seven months with preexchange plasma phytanic acid values between 480 and 800 micromol/l. Hungerbuhler ${ }^{14}$ treated his patient with 10 intermittent small exchanges over a period of 13 months to remove the phytanic acid being ingested at the restricted rate of 64 micromol per day. PE was performed with plasma phytanic acid levels of 2038 to $818 \mathrm{micromol} / \mathrm{l}$. Subsequently the patient was placed on a diet containing not more than 32 micromols of phytanic acid per day and plasma levels remained below the preexchange values.

Dickson et al $^{15}$ treated a severely affected nine year old boy with 11 PEs in the first six months after the diagnosis and then recommenced further treatment after an interval of six months because dietary restriction did not reduce his plasma phytanic acid levels sufficiently. In total he had 30 PEs over 19 months and a calculated 8 grams of phytanic acid were removed.

The pathological findings in untreated HAP have been subdivided into several groups. ${ }^{3}$ Of the reversible conditions cardiac arrythmias are the most life threatening. The results presented here showed that in the four patients with cardiac arrhythmias, the arrhythmias ceased immediately after PE. Ichthyosis disappeared and appetite improved in all five patients within a few weeks of PE. The partially reversible conditions of sensorimotor neuropathy and ataxia began to improve within a few weeks of PE. The longterm patients whose plasma phytanic acid continued to decline on dietary management had further gradual improvement over many years. Impairment of renal tubular function occurs in HAP. ${ }^{16}$ In the two patients tested aminoaciduria resolved after PE. There was slight improvement in the anosmia and deafness in some patients. Visual field defects and cataracts did not benefit from decreased plasma phytanic acid levels. Dietary control ${ }^{17}$ is generally effective and was adequate in most of the 22 patients attending our unit.

Hungerbuhler ${ }^{14}$ fasted his patient for 24 hours before PE on one occasion to increase the plasma phytanic acid and the yield in the plasma exchange fluid. Our first patient was starved for 48 hours and during this time his phytanic acid rose from $2820 \mathrm{micromol} / 1$ to $5897 \mathrm{micromol} / \mathrm{l}$ with concomitant severe cachexia and, in spite of the starvation, marked anorexia. In retrospect this was dangerous because it increased the cardiac abnormalities and the risk of death. In the fat stores phytanic acid does no harm, but when it is released into the plasma, as in starvation, it is toxic.

$\mathrm{PE}$ is best limited to patients with plasma levels of phytanic acid above $900 \mathrm{micromol} / \mathrm{l}$, patients not complying with the diet or cases when the diet is ineffective. In the four of our patients with an initial plasma phytanic acid above $2000 \mathrm{micromol} / 1$ large amounts were removed by PE leading to marked clinical improvement. The patient with only moderately elevated plasma levels lost a smaller amount of phytanic acid and the benefit was less marked.

The risks of PE are significant, especially if used longterm. ${ }^{18}$ Ventricular ectopic beats without haemodynamic disturbance occurred in two patients. Another patient developed an urticarial rash which responded to hydrocortisone and was possibly due to the use of fresh frozen plasma as the exchange fluid. ${ }^{19}$

In conclusion PE is beneficial for very ill patients with HAP and high plasma phytanic acid levels and this is the main indication for its use. In the majority of patients dietary restriction of phytanic acid is sufficient although PE can be considered when dietary control is inadequate.

We thank Dr J Rees who referred patient 4, Dr F Clifford Rose under whom patient 5 was treated and Drs $P$ Mayne, Burston and Guam Mei for the laboratory data for the fifth patient. We are grateful to the North West Thames Regional Health Authority frateful to the North West Thames Regional Health Authority for a research grant and to the British
Society for support and a grant to MCS.

1 Refsum S. Heredoataxia hemeralopica polyneuritiformiset tidligere ikke beskrevet familiaert syndrom? Nordisk Medicin 1945;28:2682-5.

2 Stokke O, Try K, Eldjarn L. Alphaoxidation as an alternative pathway for the degradation of branched-chain fatty acids in man, and its failure in patients with Refsum's Disease. Biochemica Biophysica Acta 1967;144:271-84

3 Gibberd FB, Billimoria JD, Goldman JM, et al. Heredopathia Atactica Polyneuritiformis: Refsum's Disease. Acta Neurologica Scand 1985;72:1-17.

4 The utility of therapeutic plasmapheresis for neurological disorders-consensus conference. J Am Med Assoc 1986;256:1333-7.

5 Plasma exchange for neurological disorders. Lancet 1986;ii:1313-4.

6 Behan PO, Behan WMH. Plasma exchange in neurological diseases. $B M J$ 1987;295:283-4.

7 Eldjarn L, Stokke O, Try K. Biochemical aspects of Refsum's disease and principles for the dietary treatment In: Vinken PJ, Bruyn GW, eds. Handbook of clinical neurology: metabolic and deficiency diseases of the nervous system. Amsterdam: North Holland, 1976:519-41.

8 Tsai S-C, Herndon JH, Uhlendorf BW, Fales HM, Mize CE. The formation of alpha-hydroxy phytanic acid from phytanic acid in mammalian tissues. Biochemical and Biophysical Research Communications 1967;28:571-7.

9 Gibberd FB, Billimoria JD, Page NGR, Retsas S. Heredopathia Atactica Polyneuritiformis (Refsum's Disease) treated by diet and plasma exchange. Lancet 1979; i:575-8.

10 Britton TC, Gibberd FB, Clemens ME, Billimoria JD, Sidey MC. The significance of plasma phytanic acid levels in adults. $J$ Neurol Neurosurg Psychiatry 1989;52:891-4.

11 Lundberg A, Lilja LG, Lundberg PO, Try K. Heredopathia Atactica Polyneuritiformis (Refsum's Disease): Experiences of dietary treatment and plasmapheresis. European Neurology 1972;8:309-24.

12 Penovich PE, Hollander J, Nusbacher JA, Griggs RC, MacPherson $J$. Note on plasma exchange therapy in Refsum's disease. Advances in Neurology 1978;21:151-62.

13 Moser HW, Braine H, Pyeritz RE, Ullman D, Murray C, Asbury AK. Therapeutic trial of plasmapheresis in Ref- 
sum disease and in Fabry disease. Birth Defects. Original Article Series 1980;16:491-7.

14 Hungerbuhler JP, Meier C, Rouselle L, Quadri P, Bogousslavsky J. Refsum's Disease: Management by diet and plasmapheresis. European Neurology 1985;24:153-9.

15 Dickson N, Mortimer JG, Faed JM, Pollard AC, Styles M, Peart DA. A child with Refsum's disease: successful treatment with diet and plasma exchange. Developmental treatment with diet and plasma exchange. Deve

16 Pabico RC, Gruebel BJ, McKenna BA, et al. Renal involvement in Refsum's disease. Am J Med 1981;
70:1136-43.

17 Steinberg D, Mize CE, Herndon JH, Fales HM, Engel WK, Vroom FQ. Phytanic acid in patients with Refsum's syndrome and response to dietary treatment. Arch Int Med 1970;125:75-87.

18 Hazards of apheresis. Editorial: Lancet 1982;ii:1025-6.

19 Rosenkvist J, Berkowicz A, Holsoe E, Sorenson H, Taaning E. Plasma exchange in myasthenia gravis complicated with complement activation and urticarial reactions using with complement activation and urticarial reactions using fresh/frozen plas 